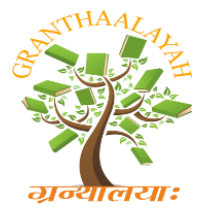
INTERNATIONAL JOURNAL OF RESEARCH GRANTHAALAYAH A knowledge Repository

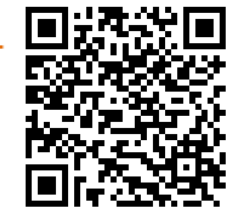

Social

\title{
A LITERATURE REVIEW ON THE DEFINITION AND MEASUREMENT OF THE CONCEPT OF GENIUS
}

\author{
Syeda Rakhshanda Kaukab"1, Syeda Amna Zubia \\ ${ }^{1}$ Department of Education, Sindh Madressatul Islam University, Karachi, PAKISTAN \\ ${ }^{2}$ MBBS Student, Ziauddin University, Karachi, PAKISTAN
}

\begin{abstract}
Genius is a concept which has still not been fully explored. Although genius has been linked to intelligence and at other times to madness, still this concept is open to interpretation. This research attempts to collate and explore the major researches and literature available for this concept. The importance of this research lies in the current educational scenario globally which aims at all children passing through the routine education which does not distinguish between students of higher capability and average capacity and treats all as a set of equal, indistinguishable herd. The research identified that individuals with above average talents in multiple subjects are not widely acknowledged as genius, with the exception of Leonardo da Vinci. Genius tends to be associated with individuals who have excelled in only one particular field.
\end{abstract}

Keywords:

Genius, IQ, Intelligence.

Cite This Article: Syeda Rakhshanda Kaukab, and Syeda Amna Zubia, "A LITERATURE REVIEW ON THE DEFINITION AND MEASUREMENT OF THE CONCEPT OF GENIUS" International Journal of Research - Granthaalayah, Vol. 3, No. 11(2015): 21-31.

\section{INTRODUCTION}

Before going into the details of the purpose of this research, a small exploration of the roots of the word genius is in order. In ancient Rome, the tutelary deity or patron of a person, family or place was referred to as the "genius" for that particular subject. (Genius, n.d.) A combination of the Latin verb, genui or geniti, which means "to create, produce or bring into being", and the noun ingenium, referring to man's inherent abilities and characteristics, the modern-era term "genius" refers to a person with extraordinarily superior mental capabilities and creativity (Robinson, 2010).

Early Romans did not necessarily combine genius with intellect. This notion evolved in the eighteenth century after the Enlightenment, when a genius became a person with exceptional mental and creative powers, whether innate, acquired or both. The word "genius" was already in common usage by 1711, when poet, playwright and politician Joseph Addison wrote in his journal 
The Spectator, "There is no character more frequently given to a writer than that of being a genius. There is not a heroic scribbler in the nation that has not his admirers who think him a great genius". (Robinson, 2010)

This excessive creativity and originality more often than not lead to innovative advances and eminent achievement. Therefore, even though the existence of genius has been oft questioned and there appears to still be no definite meaning of the word, psychologists are now formulating a definition which combines the elements of creativity and accomplishment.

All around us we see the discussion on the term genius and who to classify as genius with the general trend being to title anyone with extraordinary invention or prowess in a particular field as a genius, such as Albert Einstein, Isaac Newton, Blaise Pascal, John Stuart Mill, Archimedes, etc. However, the questions is whether this is the true criteria to define a genius. Or should a genius be someone who is multi-talented with an extraordinary skill in a particular field such as Leonardo da Vinci who was not only a great painter but had the most amazing ideas of his time such as a helicopter, a tank, solar power, a calculator, and a theory of plate tectonics. The thought also arises whether someone who was an excellent lawyer, exploiting the weaknesses of the prevalent laws of the time to help the victims, an extraordinary orator and a remarkable politician and statesperson be labelled a genius despite not fulfilling the traditional measure of IQ - Mohammad Ali Jinnah.

The purpose of this research is to examine the development of the concept of genius over time and the current theories and measurements in place to define a genius. This paper would also attempt to identify the gaps in the research on categorising and measuring genius.

\section{DISCUSSION AND ANALYSIS}

\section{Does Sudden Genius Exist?}

First this research will explore the work of Andrew Robinson who evaluated the possibility of whether a person could suddenly gain a genius or in other words extraordinary insight without hard work. He studied the idea of whether intelligence or a higher utilisation of brain power without laborious efforts exists. While society has long since equated genius with intelligence, genius has more to do with productive creativity. The exceptional output from such people is multifactorial, emerging from genetics, opportunity and effort. Innate ability, temperament, circumstances and rare level of motivation all coalesce to be seen in the achievement of a genius. It can be argued that no heights of intelligence can lead to innovations and discoveries without a certain amount of time, skill and determination being put into the matter at hand. While Archimedes' Eureka seems to counter this argument, even his apparent epiphany was the result of a long and laborious thought process. (Robinson, 2011) This exactly can be seen described in Thomas Edison's oft-quoted remark, from around 1903, "Genius is 1 per cent inspiration, 99 per cent perspiration," and Albert Einstein's "It's not that I'm so smart, it's that I stay with problems longer."

Andrew Robinson (Does Genius Follow the Ten-year Rule?, 2011) observes that the accomplishments by known geniuses and the time they took to make the discovery. There is no doubt that geniuses persisted and laboured continually and several years of hard work preceded 
any scientific discovery. To say that Alexander Fleming discovered penicillin by mistake in 1928 would be injustice to him. He had been working in the bacteriology department of a hospital for nearly twenty years before he made the discovery. Similarly, in 1984 Alec Jefferson may have forgetfully left his experiment running, but he may not have encountered genetic fingerprinting had he not looked at the strange lines on his developed film with curiosity. Both of these cases are classic examples of Louis Pasteur's statement, "Where observation is concerned, chance favours only the prepared mind."

Although genius does not seem to be limited by any laws and confines, The Ten-Year Rule has been identified by psychologists, according to which geniuses spend at least ten years in their respective field of research until they come across a ground-breaking invention. Rarely have any revolutionary innovations been achieved in less than ten years. Most notable from the sciences is Albert Einstein, who presented and published his Theory of Relativity in 1905, his first insight into special relativity having been in 1895. August Kekule's theory of the structure of the benzene molecule was published ten years after he first daydreamed about the structure. Tim Burners-Lee invented the World Wide Web a decade after his first web-like software. In the arts too, Shelley, Picasso, Stravinsky, all produced their first universally accepted masterpieces ten years after their first work in the field, be it literature, art or music.

Studying all these cases defines more clearly that while all these innovators may have had their fair share of moments of "sudden inspiration", there was a background of hard labour and determination which paved the pathway to their creative discoveries.

\section{INTELLIGENCE AND GENIUS}

Having determined that the Andrew Robinson refuted the idea of sudden genius which was also substantiated by the study of the various individuals who are widely accepted as genius; the researcher next focused on the researches that have linked a higher level of intelligence with genius. Very less reliable quantitative data is available regarding the intelligence of past and present geniuses. Intelligence testing only began in the 20th century, with Binet's test for mental retardation in French schools. (Cherry, IQ (Intelligence Quotient) Testing: Brief History) Hence no numerical data is available for before that. Secondly, these tests are carried out in the youth, hence psychologists often fail to discover a potential genius before his exceptional creativity and talents begin to shine through. Moreover, not many people considered to be geniuses would opt for sitting in any standardised test, mainly as intelligence testing is still not looked upon too favourably. Test scores are not mentioned on college applications or curriculum vitae, nor in reference books, questioning the credibility of such scores.

Nevertheless, those geniuses who were measured for intelligence during their school days, more often Nobel laureates, scored relatively low in these tests, many even failing to reach the 135 which indicates "gifted intelligence". In 1921, Lewis Terman, a noted psychologist, began a survey of gifted children at Stanford University. While his programme missed out on documenting future Nobel laureates due to their low scores, it should be noted that none of Terman's "gifted children" grew up to win a Nobel or Pulitzer Prize. 
The principal problem in drawing a parallel between intelligence and exceptional creativity and genius is that while intelligence can now be measured by psychologists, there still does not exist a definition for genius. Robert Sternberg admitted in 1986 that even though there are innumerable tests to measure intelligence, it is not quite certain what intelligence is nor what the available tests have been measuring. Hence, to measure intelligence and genius, there first needs to be an approximate definition of what needs to be measured.

\section{STUDY OF GENIUS}

The scientific study of genius began in the nineteenth century, with Sir Francis Galton's publication "Hereditary Genius: An Inquiry into its Laws and Consequences" (1869). Galton took a paramount interest in his Cousin Darwin's work and launched a study into how genetics plays a role in the intelligence of any individual being. He conducted detailed research into the lives, history, achievements and families of illustrative individuals and their kin to establish the genetic factors which contribute to intelligence, convinced that genetic traits passed on through generations are what contribute to genius and eventually success. Biographies and obituaries of politicians, authors, poets, judges, scientists, artists, musicians, athletes and clergymen were studied to identify eminent lineages. (The Occidental Observer, 2009)

The basic observation Galton noted which led to further investigation was that of all the individuals he studied, the ones who could be claimed to have exceptional creativity or genius had more such people in their family who were noteworthy. Having studied over 500 noblemen who had achieved some feat within their lifetimes that set them apart from the others, Galton discovered that each had a close blood relation, or more than one, who had similarly stood out with a great accomplishment. Galton himself belonged to a family of notables, relatively inbred, who all had highly intellectual interests. Hence the individuals who attained prominence in their professions tended to have a greater proportion of similarly endowed relatives as compared to other mediocre individuals.

Galton also believed that the success of any person with inbred intellectual genius would not be daunted by obstacles presented by his society, background or upbringing. Such individuals can combat all these hardships and their ideas will find a light. But as he proposed that genius can be inherited the same way all qualities are inherited by all living, reproducing organisms, he also recognized that external factors and motivations, such as capability, enthusiasm and the tendency for hard work are major influencing factors. He devised several measures of intelligence, relying on statistics, including the psychometric and historimetric approaches to study his propositions. While there has been severe criticism of Galton's theories and his adamant efforts to promote his brainchild eugenics and sterilize the feeble-minded to give birth to a super nation, they have widely inspired future researchers to work towards validating the connection between heredity and genius. (Human Intelligence: Francis Galton, n.d.)

The next major study in this direction was done by Lewis Terman, who introduced the word IQ to our dictionaries and revised the Stanford-Binet test to develop IQ testing to as we know today. His tests included questions from mathematics to vocabulary to grasp "general intelligence". Like Galton, Terman, a strong believer in eugenics himself, was convinced that genetics played a major part in defining the level of the vital constant of an individual's intellectual capacities, unaltered 
by home, environment or effort. This constant he termed as “Intelligence Quotient". (Leslie, 2000) However, Terman was mainly determined on proving the general notion that geniuses were les tall and developed, socially inept, unamicable, awkward and geeky, while being incredibly low in intelligence as children.

Terman published his book, entitled "The Measurement of Intelligence" (Terman, 1916), which included an IQ test which a child could complete on the inside of 50 minutes. This testing method became so common throughout America that rarely any students have passed through the American school system without having taken the Stanford-Binet test or one of its rivals. The test quickly became a customary procedure while testing candidates for schools, colleges, universities, professions and government institutions. It provided educators with a cheap, easily available, easy to attempt and efficient to evaluate students for intellect and to assign them to courses according to their aptitude. It reformed what students learned and their self-image.

When this testing method reached the Army to recruit individuals for the First World War, more than 1.7 draftees sat for Terman's test, rapidly increasing public awareness and acceptance of IQ testing. Suddenly Terman found himself the leader in a dedicated movement to take testing nationwide and to test each child and adult to stratify society. The proponents in this movement considered intelligence the most prized human quality, which distinguished man from animal. This group included many eugenicists who saw this as a means to contrive a nation of fitter and more efficient individuals. They believed that the most rewarding jobs in all professions and the academia should only be conferred to those who performed well in these tests and had an above average IQ. On the other hand, the people with low scores would be institutionalized and prevented from producing children.

Terman's study, "Genetic Studies of Genius" (today known as the "Terman Study of the Gifted") has proven to be the longest running longitudinal study at Stanford's Psychology Department. Originally intended to study the development and characteristics of the gifted children throughout their adolescence and into their adulthood. Over time, the participants kept in touch with the department and regularly submitted complete questionnaires and surveys, and the study was expanded to include more study areas. A total of 1528 individuals were included in the study and their lives, education, personal life, careers, health and opportunities were scrutinized. (Terman, Genetic Studies Of Genius: Mental And Physical Traits Of A Thousand Gifted Children, 1926) These children have been affectionately called "Termites" over the years. Terman became their parent, mentor and guidance counsellor, first for their careers, then increasingly for their lives and personal matters. Having spanned over most of the 20th century, this study has become a valuable resource for studying the effect of time and circumstances upon individuals and their thinking and personality.

From this study, Terman concluded that these children were bright, tall, well-rounded and had sound mental capacities, and in all obvious ways, very normal individuals. However, being normal also meant that these children were no more and no less stable than the general population, meaning the divorce, suicide and alcoholism rates were also similar. (Terman Summary, n.d.) While none of them went on to win a Nobel or a Pulitzer Prize, several prominent figures have emerged, namely physiologist Ancel Keys, who discovered the link between cholesterol and heart disease; physicist Norris Bradbury, former director of the Los Alamos National Laboratory; 
journalist Shelley Smith Mydans; and Hollywood luminaries Edward Dmytryk and Jess Openheimer. We also know that two of the children from the group that was tested but didn't qualify to be part of the study, William Shockley and Luis Alvarez, did both win a Nobel Prize. However, the relevance of this event can be questioned has well, as Shockley belonged to a group who earned the Nobel, and Alvarez's native language was not English which may have caused him trouble in attempting the test which set them apart. Nonetheless, it can safely be concluded that geniuses may not stand out from the rest during their childhood except maybe in early learning faculties, and they can grow up to be normal, healthy, social individuals who do not face any social isolation. Any major differences in the success levels within the group turned out to be as a result of self-confidence, perseverance and early parental encouragement. (Cherry, Are People with High IQs More Successful?)

Since then, several successive researches have been undertaken, but all have been based on the above two studies. They have however helped develop a more complex understanding of human intelligence and the factors owing to the combination that makes a genius.

\section{CORRELATION OF MADNESS AND GENIUS}

Psychologists have defined five broad personality domains i.e. The Big Five, which have been used to classify personality types. The Big Five include openness, agreeableness, extraversion, conscientiousness and neuroticism. Of these, the most related to critical thinking and creativity is the trait Openness to experience. (Cherry, What Are The Five Major Personality Traits?)

At one end of the spectrum for this domain is the inventive/curious personality, as opposed to the consistent/cautious personality at the other. Personalities with strong traits from this domain tend to have an appreciation for art, adventure and sentiments. They are very curious and enjoy diversifying their experiences. Unusual ideas and creativity appeal to them. The degree of intellectual inquisitiveness, originality and the preference for new experiences a person has are all reflected within the domain of Openness. Their imagination, independence and taste for variety are what make a personality stand out for this description. High openness reflects unpredictability and a lack of focus, while low openness people tend to follow strict routines and are rational. Disagreements still exist regarding the interpretation of the Openness factor, which is also referred to as "intellect".

It is within this domain, studies have indicated, that the origin of genius lies. Most "geniuses" have known to renounce tradition and routine, exploring their gifts beyond the ordinary. They think out of the box, come up with brilliant original ideas and question everything. It is this curiosity and thirst for knowledge and explanations that leads them to achieve new horizons and breakthroughs which were never even thought of before. This points towards a highly developed Openness/Intellect trait at the far end of the spectrum. While such individuals were highly noted for their discoveries, they were also known to have a very high disregard for social norms and personal hygiene, which often made them the subject of criticism.

Geniuses have also been known to exhibit a higher degree of psychoticism, as demonstrated by Hans J Eysenck, a near-genius psychologist himself, in his book "Genius: The Natural History of Creativity". (1995) He was one of the very few psychologists who seriously tackled with the 
question of genius. In his book, he describes the quintessence of genius to be a mixture of extraordinary intelligence with originality, suggesting that creativity is the starting point while intelligence provides the evaluation required to reach that conclusion. Hence, most of Eysenck's work focussed on correlating creativity Psychoticism and Creativity.

The psychoticism trait follows three broad strands. Firstly, there is the psychotic aspect of this trait, which is basically characterized by a thinking style not commonly accepted or followed i.e. thinking out of the box. Individuals who display this thinking often find patterns normally not seen and an association between concepts which would ordinarily be missed by people. While such rationale would be commended if it led to any positive outcomes, too much of this aspect can be considered as positive schizotypy or apophenia (false detection of patterns or causal connection). While in the general population apophenia may cultivate into a causeless obsession with a ritual or random occurrences which do not have any plausible explanation, for example wearing luck charms or seeing religious figures on a slice of toast or halved tomato (hence termed psychoticism), in individuals with a high intelligence, such an ability results in their being able to perceive important patterns other people may have missed. This ability leads to breakthroughs in science and arts which may not have otherwise been possible. (Kaufman, 2012)

Eysenck argues that while different people may have different ways of perception, some may be more narrow-minded than others, the people who expand their ideas and draw ideas from memory. This can be considered analogous to recalled dreams, in which one memory reminds from another, and all the abstract trains of thought seem illogical without a tight rational connection. Present in several psychotic illnesses and intoxication, this trance-like state is also described by several creative people. Eysenck suggests that these people have an over-inclusive style of thinking, providing a larger sample of ideas on which an evaluation can be drawn. They tend to derive from memory previously existing ideas and although they may seem irrelevant to each other, they find a logical explanation linking them, resulting in new and creative solutions for problems. Hence their innovative and unusual ideas become more efficient and applicable than the ideas that could be thought up by more narrow-minded people with a conventional thinking. Ultimately, this could be the base from which geniuses draw their creativity.

Psychophysiologically, Eysenck discovered that such over inclusive thinkers are more likely to be of a personality that closely relates to that of a schizophrenic or any other person with psychosis. But while the psychoticism score of the genius is just as high as the diagnosed psychotic, he is not necessarily a diagnosable psychotic. Eysenck also presented evidence that has proven the relationship between insanity and genius, saying that true geniuses have a high score on personality tests for psychoticism. It can also be reliably stated that unusual and strange responses to word association tests can be used to measure psychosis, noncompliance to convention and creativity. (Porzio, 2013)

It has been known for years that distinguishingly intelligent people are more likely to suffer from manic depression, bipolar disorder or other psychoses, as compared to the general population. Researchers at Stanford University, through conducting personality and temperament tests, found healthy artists' personality to be more similar to individuals with manic depression, as compared to individuals in the general population. They concluded that emotional range was what gave psychotic individuals an edge over others and that is what relates them to artists. Analysis showed 
that artists and manic depressives were more likely to exhibit openness, moodiness and neuroticism than those in the healthy control group. The latter two traits are also known as "negative-affective traits" along with mild, nonclinical forms of bipolar disorder and depression. (Stanford Report, 2002)

Secondly, relating Psychoticism and creativity is the lack of Conscientiousness which demonstrates the ability to sustain along a line of work which may be mundane for future gratification. This lack results in spontaneity, unpredictability and lack of concentration. It also causes the individual to prefer rapid gratification as opposed to delaying gratification, even if the reward later may be greater. This aspect of Psychoticism is quite the opposite of the Personality trait of Conscientiousness, lying at the far negative end of the spectrum.

Thirdly, a lack of Agreeableness may be found in the individuals displaying psychoticism, with an emotional detachment, lack of empathy, selfishness, and being an introvert. This results in them not working towards avoiding conflict and often getting into scrapes and being considered an overall unamiable person.

All these aspects together indicate a relatively high psychoticism, but also shows that the darker side of creativity and genius tends to make such individuals outcasts as their traits are socially awkward or undesirable. Collectively, Eysenck's concept of high Psychoticism and Genius together puts together a personality that can be often seen in history, as the respected, but feared and isolated Prophets of the Old Testament or the eccentric mad scientists.

Correspondingly, in "The Essential Psychopathology of Creativity" (2010), Andrea Kuszewski records that it is the extreme tails of each trait's personality spectrum where the interesting individuals are present. Most of the people diagnosed with bipolar disorder, Schizophrenia, ADHD and other psychological condition have traits which openly point to psychosis, but these people also have high cognition paired with the negative traits. These are the people who may emerge as creative intellectual geniuses so often admired in the world.

A study titled "From madness to genius: The Openness/Intellect trait domain as a paradoxical simplex", concluded that both madness and genius are positively related to the trait of Openness/Intellect. While madness may be confusion about reality, genius is characterized by penetrating perception of reality. Without the apophenic tendency to observe patterns, fundamental to Openness, an individual's intellect is unlikely to lead to the ingenuity requires for genius to express itself. Hence it is most incumbent that one risk insanity to accomplish genius. (DeYoung, Grazioplene, Peterson, 2011)

\section{GENIUS AND MODERN AGE}

In today's Information Age, with quickly advancing society and major breakthroughs at the speed of light, thanks to technology, it has become increasingly difficult to draw the line where intellectual capacity ends and electronic capacity begins. In the past, even the smallest of discoveries required years of sheer hard work. Today, we see something new every day making its niche in the market. 
While polymaths are often called "Universal Geniuses", being a polymath i.e. a person whose expertise spans a significant number of different subject areas, is not the same thing as being a genius. The development and mental expansion of polymaths depends on access to information and the quest for knowledge rather than just intellectual capacity. In modern society, the design of the education system forcing children to opt for a single field at an early age seems to have pretty much ended the reign of polymaths. Individuals like Leonardo da Vinci, Johann Wolfgang von Goethe, Aristotle and Blaise Pascal all emerged as experts in several fields due to their vast exposure. Da Vinci specifically has been regarded as the ultimate polymath, being a painter, sculptor, architect, engineer, physicist, astronomer, anatomist, humanist, biologist, geologist and a philosopher. He is often described as "the most Universal Genius"... whose outlines can only be surmised, never defined.” (McMahon, 2013)

While in the past, especially in French society, polymaths were considered the epitome of high intellect, modern society isn't so generous upon polymaths now, oft criticising polymaths as having no sense of direction, described by phrases as "Jack of All, Master of None". Now the society, as well as individuals with high IQ are restless with normalcy and have an urge for progressiveness.

Modern mainstream ideas of creativity are plays upon pseudo-creativity, and are usually limited to the trait Openness to Experience, including individuals who are willing to expand beyond their comfort zone. Openness creativity has many charms and advantages over genuine creativity bordering on psychoticism, but it has been regarded as an opportunistic fake. Indeed, in modern society, all academics and scientists are almost uniformly high Openness type individuals. Due to the prevalence of personality testing at nearly all stages of professional lives, the candidates high in trait Psychoticism are filtered out by prolonged and multistep selection processes. The end pool comprises mostly of women, who are lower in this trait, and those individuals who would be more likely to behave stably and be predictable.

As a result, in modern educational and research institutions, the situation is much better for everyone with regard to the environment. There are more stable employees and colleagues present, who conform and do not try to question too much or think too out of the box, resulting in a disruptive environment. However, these are the very qualities which end up making this situations unreliable as they do not reflect the true potential of the society.

\section{CONCLUSION}

From the above exploration of the various researches conducted in defining and measuring genius, we can conclude that to date there is no universally acceptable definition of genius Furthermore, although measurement tools have been developed to identify the intelligence levels of individuals and filter out psychoticism, there is no reliable measure of genius. While the modern educational methods are discouraging polymaths, still this aspect is open for further research and exploration. It is to be seen whether the educational institutions are forcing masses to think alike and are churning out individuals conditioned to react in a specific way, think within a particular set of beliefs and thus preventing the true potential and creativity of individuals from developing, While the world advances, we see individuals paving their way forward, regardless of their background, and while this is very encouraging, more studies need to be conducted and awareness increased to 
look into genius in depth: genetic origins, influences, development and impact on the future of the individual, the generation and the society as whole.

\section{REFERENCES}

[1] Cherry, K. (n.d.). Are People with High IQs More Successful? Retrieved from about education: http://psychology.about.com/od/intelligence/a/does-high-iq-equal-success.htm

[2] Cherry, K. (n.d.). IQ (Intelligence Quotient) Testing: Brief History. Retrieved from about education: http://psychology.about.com/od/psychologicaltesting/a/int-history.htm

[3] Cherry, K. (n.d.). What Are The Five Major Personality Traits? Retrieved from about education: http://psychology.about.com/od/personalitydevelopment/a/bigfive.htm

[4] DeYoung, Grazioplene, Peterson. (2011). From madness to genius: The Openness/Intellect trait domain as a paradoxical simplex. Journal of Research in Personality.

[5] Eynseck, H. J. (1995). Genius: The Natural History of Creativity. Cambridge University Press.

[6] Galton, F. (1869). Hereditary Genius: An Inquiry into its Laws and Consequences. Retrieved from http://galton.org/books/hereditary-genius/text/pdf/galton-1869-geniusv3.pdf

[7] Genius. (n.d.). Retrieved from Dictionary.com: http://dictionary.reference.com/browse/genius

[8] Human Intelligence: Francis Galton. (n.d.). Retrieved from Human Intelligence: http://www.intelltheory.com/galton.shtml

[9] Kaufman, S. B. (2012, January). Must One Risk Madness to Achieve Genius. Retrieved from Psychology Today: https://www.psychologytoday.com/blog/beautifulminds/201201/must-one-risk-madness-achieve-genius-0

[10] Kuszewski, A. (2010). The Essential Psychopathology of Creativity. Retrieved from Science 2.0:

http://www.science20.com/rogue_neuron/essential_psychopathology_creativity-71831

[11] Leslie, M. (2000). The Vexing Legacy of Lewis Terman. Retrieved from Stanford Magazine: https://alumni.stanford.edu/get/page/magazine/article/?article_id=40678

[12] McMahon, D. M. (2013). Divine Fury: A History of Genius.

[13] Porzio, S. K. (2013, October). A Critical Review of Eysenck's Theory of Psychoticism and How it Relates to Creativity.

[14] Robinson, A. (2010, November). Can We Define Genius? Retrieved from Psychology Today: https://www.psychologytoday.com/blog/sudden-genius/201011/can-we-definegenius

[15] Robinson, A. (2011, February). Does Genius Follow the Ten-year Rule? Retrieved from Pyschology Today: https://www.psychologytoday.com/blog/sudden-genius/201102/doesgenius-follow-the-ten-year-rule

[16] Robinson, A. (2011, January). Is High Intelligence Necessary to be a Genius? Retrieved from Psychology Today: https://www.psychologytoday.com/blog/suddengenius/201101/is-high-intelligence-necessary-be-genius

[17] Stanford Report. (2002). Researchers find link between creative genius and mental illness. Retrieved from http://news.stanford.edu/news/2002/june12/crazy_genius.html 
[18] Terman Summary. (n.d.). Retrieved from The Mega Foundation: http://hiqnews.megafoundation.org/Terman_Summary.htm

[19] Terman, L. (1916). The Measurement of Intelligence. Retrieved from https://archive.org/details/measurementofint008006mbp

[20] Terman, L. (1926). Genetic Studies Of Genius: Mental And Physical Traits Of A Thousand Gifted Children. Retrieved from https://archive.org/details/geneticstudiesof009044mbp

[21] The Occidental Observer. (2009). Review of Hereditary Genius: An Inquiry into its Laws and Consequences. Retrieved from http://www.theoccidentalobserver.net/2009/10/review-of-hereditary-genius-an-inquiryinto-its-laws-and-consequences/ 